\title{
3-D STRUCTURE OF INDIAN FORESTS - PERSPECTIVES FROM EXPERIMENTS ON THE FIRST FULLY-POLARIMETRIC TANDEM-X TOMOGRAMS
}

\author{
Unmesh Khati $^{1 *}$, Gulab Singh ${ }^{1}$, Marco Lavalle ${ }^{2}$ \\ ${ }^{1}$ Indian Institute of Technology, Bombay, India - (khatyunmesh@gmail.com; gulab.singh@iitb.ac.in) \\ ${ }^{2}$ Jet Propulsion Laboratory, California Institute of Technology, Pasadena, CA, USA - marco.lavalle@jpl.nasa.gov
}

Commission V, SS: Natural Resources Management

KEY WORDS: Radar, Tomography, SAR, TanDEM-X, Forest, India, Tropical, Structure

\begin{abstract}
:
This paper provides a first hand view of the 3-D structure of the forests when viewed by X-band SAR data. Tomograms are generated using multi-polarimetric space-borne TerraSAR-X/TanDEM-X acquisitions and analysed over a multi-species forest range. The paper analysed these generated tomograms and puts forth-interesting observations of these unique forest species. The high- and low-canopy density plantations provide unique tomograms and vertical structure profiles where the effect of varying extinction is observed in Xband. Further, the scattering powers are shown relative to their backscatter powers. In-depth analysis in currently underway and would be reported in future.
\end{abstract}

\section{INTRODUCTION}

TanDEM-X fully-polarimetric acquisitions have been shown to have sensitivity to forest bio-physical parameters over various forest test sites globally (Unmesh Khati, Singh, and Ferro-Famil 2017; Kugler et al. 2014; Krieger et al. 2007). SAR tomography is an advanced SAR processing technique which utilizes multiple SAR acquisitions for estimation of 3-D structure of the forest (Reigber and Moreira 2000; Ferro-Famil, Huang, and Reigber 2012; Tebaldini 2010; Unmesh Khati, Ferro-Famil, and Singh 2017). Globally SAR tomography has been demonstrated using airborne SAR data over forests. However, space-borne SAR data has limited applicability for 3-D structure estimation due to limited acquisitions, temporal gap and low variance of baselines (Lombardini and Cai 2014; Lavalle and Hensley 2015). The present research work is an extension of concerted efforts to utilize multiple TanDEM-X acquisitions for generation of the first fully-polarimetric space-borne X-band SAR tomogram over a forest range (Unmesh Khati, Ferro-Famil, and Singh 2017; Unmesh Khati, Singh, and Ferro-Famil 2017; Unmesh Khati and Singh 2015; U. Khati, Singh, and Kumar 2018). The initial research work focused on evaluating the TanDEM-X pursuit monostatic acquisitions for estimation of forest height and forest above-ground biomass (AGB). Results showed surprisingly accurate forest height estimates over multiple forest test sites in India. The AGB estimation was accurate for forest ranges up to $150 \mathrm{Mg} / \mathrm{ha}$

\section{BRIEF METHODOLOGY}

For tomography study, the Haldwani forest range was selected as a suitable test site due to known forest management practices, distinct species and relatively flat topography. Subsequently, 18 fully-polarimetric TerraSAR-X/TanDEM-X scenes were coregistered, phase calibrated and focused using a Capon beamformer. Various issues such as low SNR of TanDEM-X, especially at cross-polarized channels, decorrelation and identification of sources of decorrelation are addressed and corrected for. With a well-calibrated data stack, various experiments and validations are carried out:

\section{RESULTS}

\subsection{3-D structure of the forest}

With generation of tomograms, the vertical structure of various forest field plots were generated and validated with field observations. Field work carried out in 2015 and 2017 were utilized. One such tomogram is shown in Figure 1. In this figure, the tomograms generated in 5 polarizations $-\mathrm{HH}, \mathrm{HV}, \mathrm{VV}$, $\mathrm{HH}+\mathrm{VV}$ and HH-VV are shown. The red dotted line shows the extent of the field validation plot carried out in November of 2015. The field photograph captured during the field survey is shown in Fig. 1 (b). The 3-D structure in the form of vertical scattering profile at the field plot location are shown in Fig. 1 (c). These vertical profiles are shown again in all 5 polarizations along with location of the ground (blue line) and $\mathrm{H}_{100}$ height of the plot (black dotted line). It is interesting to note the following:

a. Bare ground or grassland surrounding the Teak plot are accurately estimated and follow the ground height (MSL) shown by the black line in Fig. 1(a)

b. VV-pol signals penetrate further than HH-pol since they interact more with the trunks of the forest while HV-pol tomogram is noisy due to low SNR of TanDEM-X

c. The surface scattering dominates $\mathrm{HH}+\mathrm{VV}$ tomogram as expected since most of the scattering occurs from the top of the canopy

d. Vertical profiles in Fig. 1(c) show dominant scattering (peak power) along the canopy rather than at the top of the canopy. This is observed in the field plots where the teak canopy is spread through. 

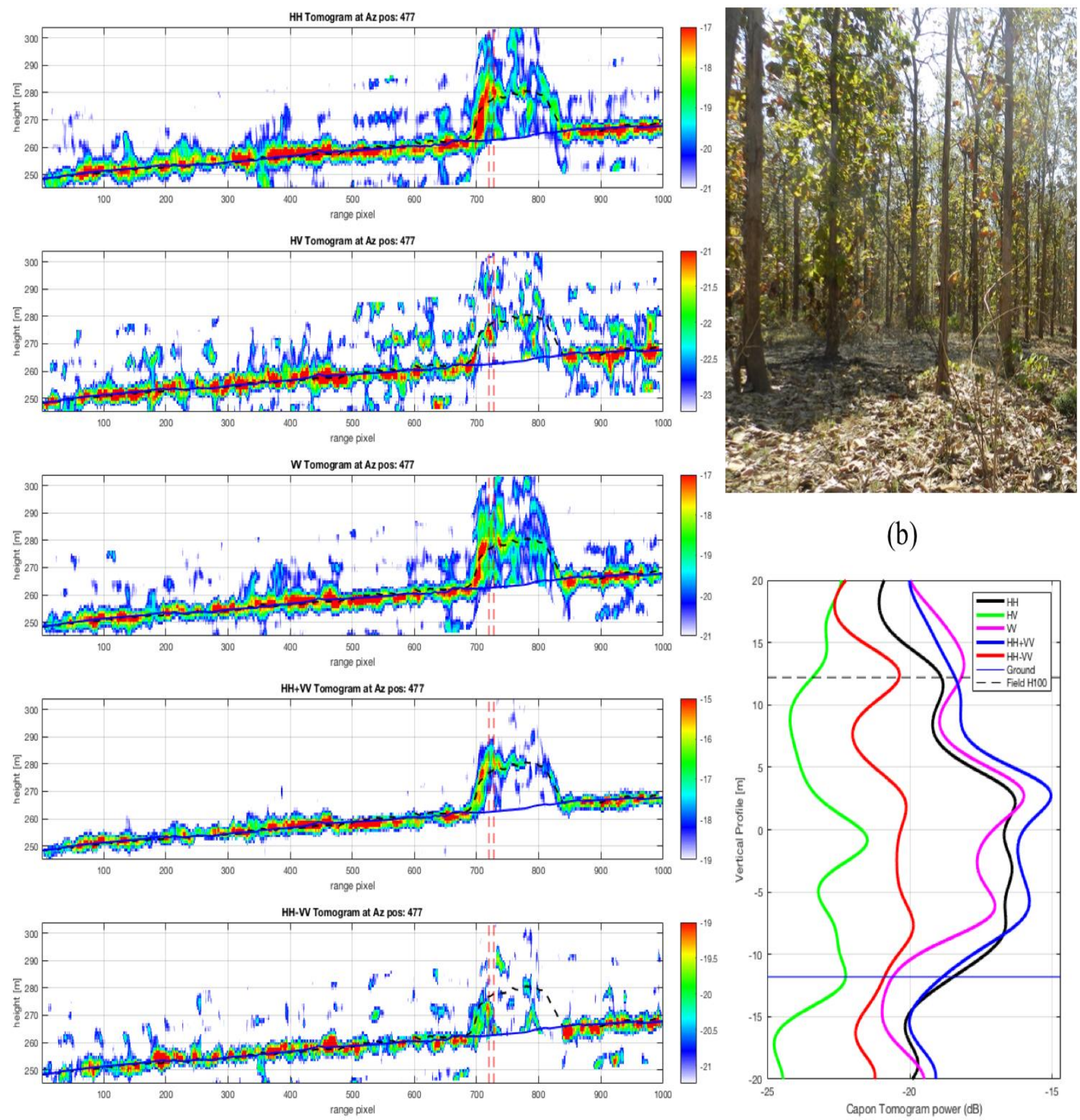

(a)

(b)

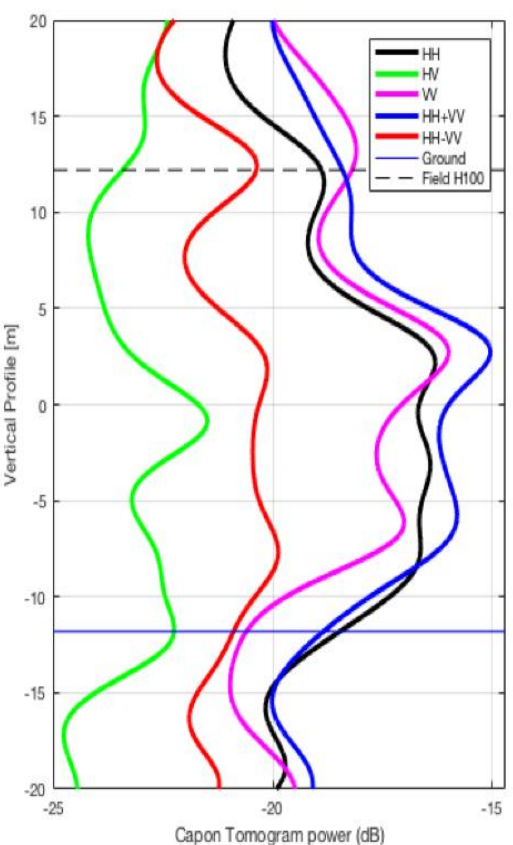

(c)

Figure 1 (a) Tomograms in 5 polarizations - HH,HV, VV, HH+VV and HH-VV over a Teak plantation in Haldwani forest range. Also shown are the (b) Field photograph captured in November 2015 and (c) the vertical profile of the field plot in the 5 polarizations. The legend describes the colours.

\section{CONCLUSIONS}

The present research work is the first attempt to utilize TanDEM$\mathrm{X}$ acquisitions for 3-D structure estimation of tropical forests. Some work has been shown for Tomography over urban areas and boreal forests using single-pol data. However, the variability of the polarimetric signature through the forest vertical structure has not been demonstrated at X-band using space-borne SAR data. This novel experiment successfully estimates the 3-D forest structure and shows a surprising penetration capability of the Xband microwaves through the test site. This is expected to be a function of the canopy gaps and row plantation of this managed forest test site. The relative power of the vertical profiles at different polarizations depicts the actual scattering power centre and attenuation through the canopy. The 3-D structure of multiple field plot locations are currently being analysed to estimate the forest stand height and forest AGB. Validation of these would be carried out and presented along with extensive analysis. 


\section{ACKNOWLEDGEMENTS}

The authors thank the German Aerospace Agency (DLR) for the TerraSAR-X/TanDEM-X data under Science Announcement of Opportunity (AO) no NTI_POLI6937. The authors thank the Uttarakhand State Forest department for their support extended during the field campaigns. A part of this work was carried out at JPL-NASA under the Fulbright-Nehru Doctoral Fellowship Program 2017-18.

\section{REFERENCES}

Ferro-Famil, Laurent, Yue Huang, and Andreas Reigber. 2012. "High-Resolution SAR Tomography Using Full Rank Polarimetric Spectral Estimators." In 2012 IEEE International Geoscience and Remote Sensing Symposium, 5194-97. Munich, Germany: IEEE. https://doi.org/10.1109/IGARSS.2012.6352439.

Khati, U., G. Singh, and S. Kumar. 2018. "Potential of SpaceBorne PolInSAR for Forest Canopy Height Estimation Over India-A Case Study Using Fully PolarimetricL,C-, AndX-Band SAR Data." IEEE Journal of Selected Topics in Applied Earth Observations and Remote Sensing $\quad 11 \quad$ (7): 2406-16. https://doi.org/10.1109/JSTARS.2018.2835388.

Khati, Unmesh, Laurent Ferro-Famil, and Gulab Singh. 2017. "First Demonstration of Space-Borne Tomosar Using Terrasar-x/Tandem-x Full-Polarimetric Acquisitions." In 2017 IEEE International Geoscience and Remote Sensing Symposium (IGARSS), 5275-76. Fort Worth, TX:

IEEE. https://doi.org/10.1109/IGARSS.2017.8128192.

Khati, Unmesh, and Gulab Singh. 2015. "Bistatic PolInSAR for Forest Height Estimation: Results from TanDEM-X." In APSAR 2015, 214-217. Singapore: IEEE. https://doi.org/10.1109/APSAR.2015.7306191.

Khati, Unmesh, Gulab Singh, and Laurent Ferro-Famil. 2017. "Analysis of Seasonal Effects on Forest Parameter Estimation of Indian Deciduous Forest Using TerraSAR-X PolInSAR Acquisitions." Remote Sensing of Environment 199 (September): 265-276. https://doi.org/10.1016/j.rse.2017.07.019.

Krieger, Gerhard, Alberto Moreira, Hauke Fiedler, Irena Hajnsek, Marian Werner, Marwan Younis, and Manfred Zink. 2007. "TanDEM-X: A Satellite Formation for High-Resolution SAR Interferometry." IEEE Transactions on Geoscience and Remote Sensing $45 \quad$ (11): 3317-3341. https://doi.org/10.1109/TGRS.2007.900693.

Kugler, Florian, Daniel Schulze, Irena Hajnsek, Hans Pretzsch, and Konstantinos P. Papathanassiou. 2014. "TanDEM$X$ Pol-InSAR Performance for Forest Height Estimation." IEEE Transactions on Geoscience and Remote Sensing 52 (10): 6404-6422. https://doi.org/10.1109/TGRS.2013.2296533.

Lavalle, Marco, and Scott Hensley. 2015. "Extraction of Structural and Dynamic Properties of Forests From Polarimetric-Interferometric SAR Data Affected by Temporal Decorrelation." IEEE Transactions on Geoscience and Remote Sensing 53 (9): 4752-4767. https://doi.org/10.1109/TGRS.2015.2409066.

Lombardini, Fabrizio, and Francesco Cai. 2014. "Temporal Decorrelation-Robust SAR Tomography." IEEE Transactions on Geoscience and Remote Sensing 52 (9): $\quad$ 5412-5421. https://doi.org/10.1109/TGRS.2013.2288689.
Reigber, Andreas, and Alberto Moreira. 2000. "First Demonstration of Airborne SAR Tomography Using Multibaseline L-Band Data." IEEE Transactions on Geoscience and Remote Sensing 38 (5): 2142-2152.

Tebaldini, Stefano. 2010. "Single and Multipolarimetric SAR Tomography of Forested Areas: A Parametric Approach." IEEE Transactions on Geoscience and Remote Sensing 48 (5): 2375-2387. https://doi.org/10.1109/TGRS.2009.2037748. 